\title{
Design and construction of an integrated phytoremediation and bioethanol production system with the biomass of eichhornia crassipes
}

\begin{abstract}
Eichhornia Crassipes is considered a problem in different aquatic ecosystems, due to its abundance could become a solution to design and build economic and efficient treatment plants, and especially for the production of biofuels such as bioethanol. Aim of the present investigation is to design and to construct on a pilot scale a process of phytoremediation and bioethanol generation from the biomass of $\mathrm{E}$ crassipes. Materials and methods: A system was set up to evaluate phytoremediation with $\mathrm{E}$ crassipes with water loaded with chromium, determining the effectiveness of this plant to remove this heavy metal even though it is still alive in a body of water. Later, this process was carried out the biomass loaded with chromium to bioreactors to evaluate the production of bioethanol, valuing three types of biomass, one without chromium adhered and another with chromium adhered in its vegetal structure. Conclusion There was an affectation of the ethanol production of $\mathrm{E}$ crassipes due to the presence of chromium, but this production can be taken into account for the assembly of an integral system of phytoremediation and bioethanol production, taking full advantage of this biomass
\end{abstract}

Keywords: eichhornia crassipes, biomass, phytoremediation, bioethanol
Volume 2 Issue I - 2018

Uriel Fernando Carreño Sayago

Fundación Universitaria los Libertadores, Colombia

Correspondence: Uriel Fernando Carreño Sayago, Fundación Universitaria los Libertadores, Bogotá, Colombia, Email ufcarrenos@libertadores.edu.co

Received: January 12, 2018 | Published: February 08, 2018

\section{Introduction}

The Eichhornia crassipes macrophyte, also known as water hyacinth, is considered an invasive species due to its adaptability to a wide variety of ecosystems, affecting the natural balance of lagoons, lakes and so on Vankar \& Vásquez. ${ }^{1,2}$ An example of this is their strong presence in contaminated wetlands such as the yellow Juan of the city of Bogotá, where they removed almost 30 tons in 2016 Lenka et al. ${ }^{3}$

It is a plant that has been the source of many research in the world, such as phytoremediation of polluted water and energy production. In recent years it has been demonstrated that this species can be manipulated in a sustainable way and create practical solutions in different industries that pollute water and also a contribution to the energy problem facing the country. ${ }^{4-6}$

Phytoremediation with this plant represents an efficient and economical technology for the treatment of water contaminated with nutrients, heavy metals and large contents of organic matter, since it does not require sophisticated infrastructure. ${ }^{7,8}$ Different studies have taken the biomass of E. crassipes and have created water treatment plants contaminated with heavy metals and have reported significant results. ${ }^{5,7}$

Yang et al. ${ }^{9}$ sieved E. crassipes to construct a biological filter, treating industrial waters contaminated with chromium and lead, removing $60 \%$ of these metals. Also, Chisutia \& Mmari ${ }^{10}$ sieved E crassipes to treat industrial effluents, yielding efficiencies over $90 \%$ in heavy metals. In the study by Torres (2009), we analyzed the sorption capacity of dried E. crassipes by means of flow tests and found that this capacity depends on variables such as flow rate, solution $\mathrm{pH}$ and size particles.
But one of the problems generated by this type of phytoremediation treatment is the amount of biomass contaminated with heavy metals, among others. An alternative is to generate with this material a type of biofuel such as bioethanol, since this biomass of the $\mathrm{E}$ crassipes has large contents of cellulose and hemicellulose, which makes it a significant plant as biomass for the large-scale production of ethanol and hydrogen. ${ }^{11,12}$

Magdum et al. ${ }^{13}$ carried out acid hydrolysis on E crassipes, implementing sulfuric acid. The resulting hydrolyzed solution was rich in Hexose and pentoses which were used directly as substrate for the production of alcohol by batch fermentation using the Pichia stipitis NCIM 3497. Isarankura et al. ${ }^{14}$ produced bioethanol from E crassipes using a two-stage process: acid hydrolysis, followed by an alcoholic fermentation by implementing the xylose-fermentative yeast: Candida Sheatae, obtaining a yield comparable to that obtained by enzymatic hydrolysis, proving that a simple and accessible procedure can be generated at the moment of thinking about industrial scale.

Nigam $^{15}$ determined that sulfuric acid hydrolysis is the most effective pretreatment for the treatment of $\mathrm{E}$ crassipes. In one year, from a hectare covered by this plant, it is possible to produce 265 liters of ethanol. Pattra ${ }^{16}$ investigated different compounds to degrade sugar from E crassipes. Finding that Saccharomyces cerevisiae increased the alcohol content in the process. Also, Kuldiloke et al. ${ }^{17}$ developed a bioreactor to produce bioethanol from E. crassipes, providing the design parameters for this experimentation. ${ }^{18}$

In the present research, a phytoremediation system with production of bioethanol from $\mathrm{E}$. crassipes biomass was designed and constructed, evaluating the phytoremediation capacity of this plant with chromium 
solutions and also evaluating the bioethanol production capacity of the plant. biomass with adhered chromium used in this process.

\section{Methodology}

The E. crassipes was taken in the municipality of Mosquera, near the city of Bogotá, later washed with water to eliminate the mud traces as this wetland is in a high degree of contamination. Two significant processes were carried out in this research, a phytoremediation process where E crassipes was used to treat the contaminated waters with Chromium. After this experiment the biomass used to treat the waters was used to create a system made up of two bioreactors for the manufacture of bioethanol.

\section{Assembly of the experimental model of phytoreme- diation}

The dimensions of the experimental model of phytoremediation are long $40 \mathrm{~cm}$, high $15 \mathrm{~cm}$ and wide $15 \mathrm{~cm}$, where each one contains $10 \mathrm{~L}$ of water. This design is pilot scale and had 180 grams of $\mathrm{E}$ crassipes, which is the equivalent of two plants. Six experimental assemblies were performed, 3 with $620 \mathrm{mg} / \mathrm{L}$ of initial chromium and 3 with $740 \mathrm{mg} / \mathrm{L}$ of initial chromium. These chrome solutions are standardized for testing and resemble those of a tannery. The proposed evaluation of this treatment system lasted approximately 1 month. For the evaluations of this treatment system the concentrations in chromium water in $\mathrm{mg} / \mathrm{L}$ were measured. At the beginning and again every two days in the following Figure 1. It shows a system of treatment.

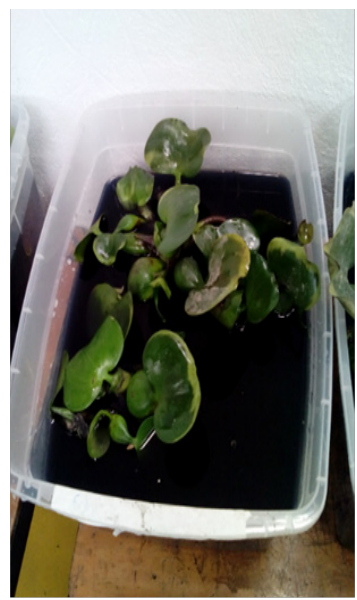

Figure I Phytoremediation

\section{Assembly of the experimental model of bioethanol production}

The biomass used in the previous phytoremediation process was used in this biofuel production process. In the next image 2, the chromium adhered to the vegetal structure is shown Figure 2. Three experiments were carried out with three different types of biomass: 1. treatment biomass of $610 \mathrm{mg} / \mathrm{L}$ of chromium, 2. the biomass of $714 \mathrm{mg} / \mathrm{L}$ of chromium and 3. Biomass without the phytoremediation process, evaluated if chromium affects the production of bioethanol of this type of biomass. Represented in the following (Table 1). The design of the bioethanol generation process consists of each experiment the construction of two bioreactors: a bioreactor to perform the hydrolyzate and a bioreactor for fermentation where it will have the entire mathematical component in the present article. For all experiments, 100grams of the biomass used in the phytoremediation process was used.

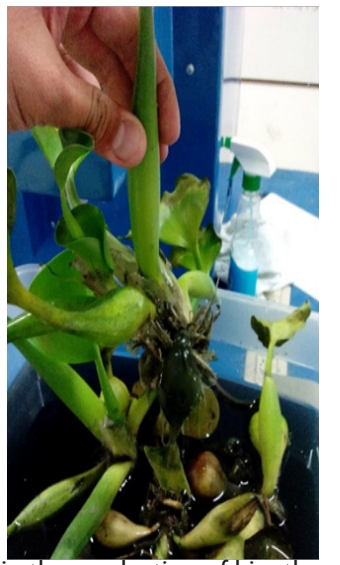

Figure 2 Biomass used in the production of bioethanol

Table I Different types of biomass

\begin{tabular}{ll} 
Experiment & Representation \\
\hline $\begin{array}{l}\text { I. biomass treatment of } 610 \mathrm{mg} / \mathrm{L} \\
\text { chrome }\end{array}$ & $\times 1$ \\
$\begin{array}{l}\text { 2. biomass treatment of } 714 \mathrm{mg} / \mathrm{L} \\
\text { chrome }\end{array}$ & $\times 2$ \\
$\begin{array}{l}\text { 3. biomass without the phytore } \\
\text { mediation process }\end{array}$ & $\times 0$
\end{tabular}

The hydrolyzate bioreactor is 2 liters in glass, has a cap for the evolution of gases, sampling $\mathrm{PH}$ and Temperature, together with a magnetic stirring heater at $120 \mathrm{RPM}$ at a temperature of $60^{\circ} \mathrm{C}$. In the hydrolyzate bioreactor the dried E. crassipes was taken, for an amount of $100 \mathrm{~g}$, where it was mixed with distilled water. The samples were reacted in $1 \%(\mathrm{w} / \mathrm{v})$ caustic soda $(\mathrm{NaOH})$ at $60^{\circ} \mathrm{C}$ for $12 \mathrm{~h}$; the samples were washed with tap water until the $\mathrm{pH}$ value of the water was reached. Subsequently, $3 \%(\mathrm{v} / \mathrm{v})$ sulfuric acid $\left(\mathrm{H}_{2} \mathrm{SO}_{4}\right)$ was added at $60^{\circ} \mathrm{C}$ for $12 \mathrm{~h}$, the samples were washed with tap water until they reached the $\mathrm{pH}$ value of the water. The content of reducing sugars was determined by the Salicylic Acid (DNS) method (Peña and Arango 2008), which indirectly quantifies the substrate consumption. 4 Liters of E. crassipes hydrolyzate solution were obtained for the continuation of Bioethanol production. The bioreactor of the fermentation is of 5 Liters in glass, with a cap for the evolution of gases, sampling of $\mathrm{PH}$ and Temperature, with heater and magnetic agitation at 120 RPM at a temperature of $60^{\circ} \mathrm{C}$. The sereciciae sacharomices was used as inoculum of the E. crassipes hydrolyzate fermenter. $100 \mathrm{~g}$ of the hydrolyzate was taken to each bioreactor where it was mixed with distilled water and $100 \mathrm{~g}$ of the inoculum was added, the initial $\mathrm{pH}$ was adjusted to 5.5. The bioreactors were hermetically sealed with rubber seals and aluminum stoppers. During the fermentation of the hydrolysis of the biomass of each type of biomass, the percentages of ethanol were tested by gas chromatography at different time intervals.

\section{Results}

\section{Results of phytoremediation}

It can be seen in Figure 3, in two days later there was a significant removal. Removals show a steady decrease of this metal, stabilizing after 24days of treatment. All three tests showed similar behavior throughout the process and removals were obtained above $70 \%$. It can be seen from the following graph 2 that the initial concentrations showed a similar behavior throughout the process and that removals were obtained above $60 \%$. Unlike the previous treatment of $620 \mathrm{mg} / \mathrm{L}$, these treatments with $714 \mathrm{mg} / \mathrm{L}$, the plant had difficulty adapting and 
after 3days were obtained removals of more than $30 \%$, stabilizing the following days. At the end he obtained 58\% removals (Figure 4).

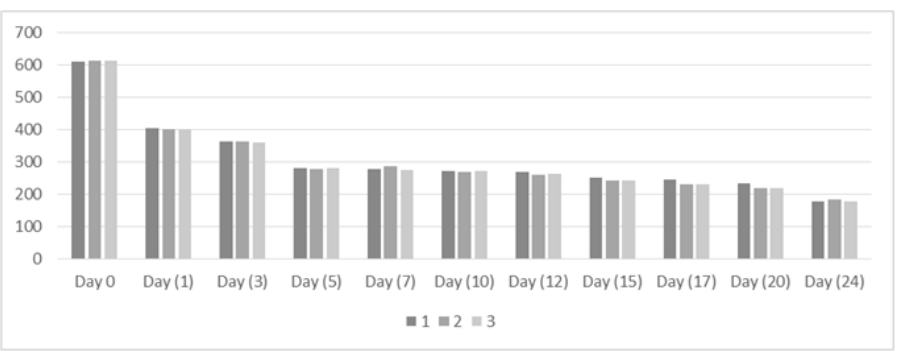

Figure 3 Phytoremediation with $620 \mathrm{mg} / \mathrm{L}$ of chromium.

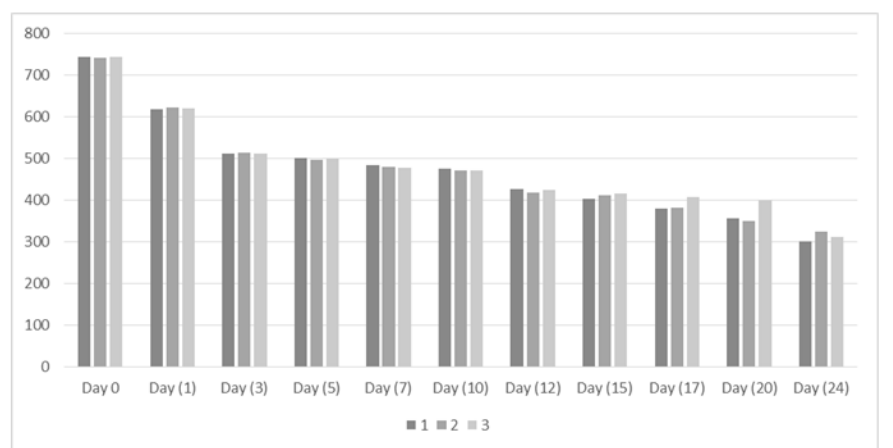

Figure 4 Phytoremediation with $714 \mathrm{mg} / \mathrm{L}$ of Chromium.

\section{Results of bioethanol production}

Sugar production through the hydrolysis of the 3 experiments was significant, in the following table shows the results of the production of each type of biomass. There was a constant production of hydrolysis, it can be observed that the concentrations of chromium adhered to the plant structure does affect the production of reducing sugars in this hydrolysis process. This hydrolyzate was passed to the next ethanol production bioreactor. A higher ethanol production for the Eichhornia sample without phytoremediation ( $\mathrm{x} 0$ ) compared to the biomass samples of 610 (x1) and 714 (x2), in a time of 24hours, is shown in Figure 5. The treatments with biomass of Eichhornia with adhered chromium began in the first 5hours to produce ethanol, in smaller amount than the biomass without chromium. In the following graph 3 , the growth and stabilization curves of each amount of biomass are observed.

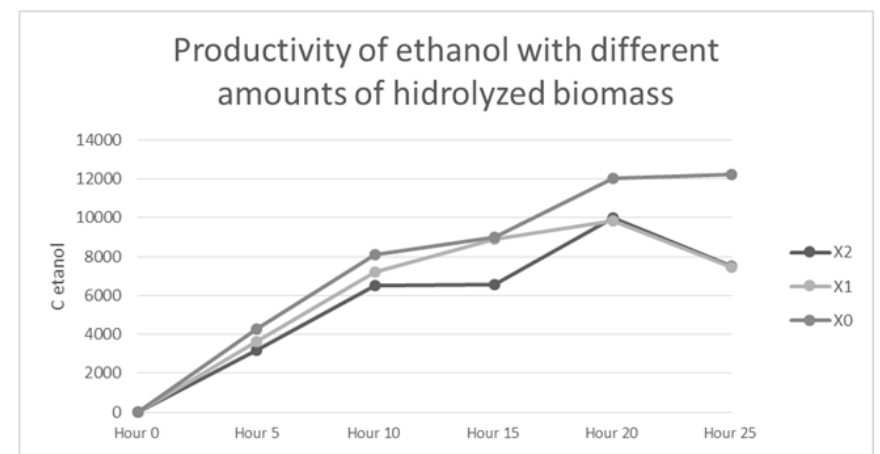

Figure 5 Productivity of ethanol with different amounts of hydrolyzed biomass

When the mass balance was carried out, it was established that ethanol production from hydrolysed biomass of E. crassipes $(\mathrm{x} 0)$ is profitable without adhered chromium, with a quantity of $12100 \mathrm{mg} / 1$ in 25 hours. For samples with adhered chromium (x1) and (x2), 25\% less ethanol was produced near $8000 \mathrm{mg} / \mathrm{L}$ in the same 25 hours, concluding that if there is an effect of the production of ethanol.

Table 2 Productivity of reducing sugars with 3 types of biomass

\begin{tabular}{lll}
\hline & Gr/L of Sugar & Yield after I 2hours \\
\hline Biomass 610mg/L $(x \mid)$ & 10 & 110 \\
Biomass 7|4mg/L) $(x 2)$ & 8 & 75 \\
Biomass of Eichhornia $(x 0)$ & 15 & 150 \\
\hline
\end{tabular}

\section{Conclusion}

E. crassipes is a viable alternative for use as a heavy metal retention agent such as chromium because of its high capacity to remove these contaminants from the water. It was observed that the hydrolysed biomass of $\mathrm{E}$ crassipes, possess a higher percentage of reducing sugars compared to the biomass with adhered chromium but this last biomass also has a good yield in the production of sugars through the hydrolyzate. The efficiency in obtaining ethanol from the 3 biomasses evaluated is interesting, considering that $\mathrm{E}$ crassipes is an unused and high quantity of waste in wetlands, rivers and other hydrosystems, could be an alternative of interest of production. There was an effect of the ethanol production of $\mathrm{E}$ crassipes in comparison to the one that did not have this metal, but this productivity can be taken into account for the assembly of an integral system of phytoremediation and production of bioethanol, taking full advantage of this biomass.

\section{Acknowledgments}

None.

\section{Conflict of interest}

Author declares that there is no conflict of interest.

\section{References}

1. Vankar PS, Bajpai D. Phyto-remediation of chrome-VI of tannery effluent by Trichoderma species. Desalination. 2008;222(1-3):255-262.

2. Vásquez B. El tratamiento de los desechos líquidos de la zona de tintura en las flores para la exportación con Eichhornia crassipes (Buchón de Agua). Revista Lasallista de Investigación. 2012;1(2):23-27.

3. Lenka M, Panda KK, Brahma B. Studies on the ability of water hyacinth (Eichhornia crassipes) to bioconcentrate and biomonitor aquatic mercury. Environmental Pollution. 1990;66(1):89-99.

4. Zimmels F, Malkovskaja A. Application of Eichhornia crassipes and Pistia stratiotes for treatment of urban sewage in Israel. J Environ Manage. 2005;81(4):420-428

5. Kasturiarachchi JC. Removal of nutrients (N and P) and heavy metals ( $\mathrm{Fe}, \mathrm{Al}, \mathrm{Mn}$ and $\mathrm{Ni}$ ) from industrial wastewaters by phytoremediation using water hyacinth (Eichhornia crassipes) under different nutritional conditions. J Environ Sci Health A Tox Hazard Subst Environ Eng. 2014;42(2):185-193.

6. Atehortua E, Gartner C. Preliminary studies of eichhornia crassipes dry biomass for lead and chromium removal from waters. Revista Colombiana de Materiales Abril de. Colombia; 2003. p. 81.

7. Martínez C, Torres M, García Cruz. Evaluación de la cinética de adsorción de $\mathrm{zn}^{2+} \mathrm{y} \mathrm{cd}^{2+}$ a partir de soluciones unitarias y binarias por raíces de eichhornia crassipes y typha latifolia. Avances en Ciencias e Ingeniería. 2013;4(2):1-14.

8. Poddar K, Mandal L, Banerjee GC. Studies on water hyacinth (Eichhornia crassipes)-chemical composition of the plant and water from different. CTF Ciencia future, Colombia; 1991. 
9. Chisutia W, Mmari O. Adsorption of Congo Red Dye from Aqueous Solutions Using Roots of Eichhornia crassipes: Kinetic and Equilibrium Studies. Energy Procedia. 2014;50:862-869.

10. Cuervo L, Folch JL, Quiroz RE. Lignocelulosa como fuente de azúcares para la producción de etanol. Biotecnología. 2009;13(3):11-25.

11. Porous M, Dhahiyat, Siregar H, et al. Studies on the uses of water hyacinth as biogas energy resource in the dam of curag (west java). In: Proceedings of the international conference on water hyacinth, Hyderabad. Chemical composition of the plant and water from different habitats. Indian Veterinary Journal. 2012;68(9):833-837.

12. Magdum SM, More AA Nadaf. Biochemical conversion of acid pretreatment water hyacinth (eichonnia crassipes) to alcohol using pichia stipitis NCIM 3497. International Journal of advanced biotechnology and research. 2012;3(2):585-590.

13. Isarankura $\mathrm{Na}$ Ayudhya $\mathrm{C}$, Tantimongcolwat $\mathrm{T}$, Kongpanpee $\mathrm{T}$, et al. Appropriate technology for the bioconversion of water hyacinth (Eichhornia crassipes) to liquid ethanol. EXCLI. 2007:521-523.
14. Nigam JN. Bioconversion of water-hyacinth (Eichhornia crassipes) hemicellulose acid hydrolysate to motor fuel ethanol by xylose-fermenting yeast. J Biotechnol. 2002;97(2):107-116.

15. Pattra S, Sittijunda S. Optimization of factors affecting acid hydrolysis of water hyacinth stem (Eichhornia Crassipes) for bio-hydrogen production. Energy Procedia. 2015;79:833-837.

16. Kuldiloke J, Eshtiaghi MN, Peeploy P, et al. Bioconversion of water hyacinth (Eichhornia crassipes) to bioethanol. Journal of ISSAAS. USA; 2010 .

17. Saprativ P, Ashutosh Gupta, Debasish, et al. Enhanced bioethanol production from water hyacinth (Eichhornia crassipes) by statistical optimization of fermentation process parameters using Taguchi orthogonal array design. International Biodeterioration \& Biodegradation. 2016;109:174-184.

18. Yang X, Chen S, Zhang R. Utilization of two invasive free-floating aquatic plants (Pistia stratiotes and Eichhornia crassipes) as sorbents for oil removal. Environ Sci Pollut Res Int. 2014;21(1):781-786. 